\title{
Pulmonary actinomycosis affecting chest wall: a case report
}

\author{
Hassan $M Z^{1}$, Uddin $M N^{2}$, Ahsan $H M N^{3}$
}

\begin{abstract}
:
Thoracic actinomycosis is an uncommon, chronic suppurative bacterial infection caused by Actinomyces species. Thoracic actinomycosis represents about one-fourth of all cases of actinomycosis. We report a case of left sided pleural effusion with hydropneumothorax with collapse and consolidation of left lung with discharging sinus in the left anterior chest wall. Actinomycosis was suspected and confirmed by microscopic identification of "sulfur granules" in the discharge of the sinus tract and also identification of gram-positive filamentous bacteria in the specimen of discharging sinus.

Keywords: thoracic actinomycosis; chest wall; lung; Bangladesh
\end{abstract}

Bangladesh Journal of Medical Science Vol. 14 No. 04 October'15. Page: 417-419 DOI: http://dx.doi.org/10.3329/bjms.v14i4.21583

\section{Introduction:}

Actinomycosis is a rare, chronic slowly progressive granulomatous infection caused by Actinomyces ${ }^{1}$. Out of 14 species of Actinomyces, six are pathogenic and Actinomyces israelii is the most common human pathogen. The Grampositive filamentous anaerobic (or facultative) bacilli is the normal flora of oropahrynx, gastrointestinal tract and female genital tract ${ }^{2}$.The most common clinical forms of actinomycosis are cervicofacial $(55 \%)$, abdominopelvic $(20 \%)$ and thoracic $(15 \%)^{3}$. Pulmonary actinomycosis results from aspiration of oropahreangeal secretion containing actinomyces ${ }^{4}$. Patient presents with haemoptysis (42\%), persistent cough $(37 \%)$, fever, dyspnea and chest pain ${ }^{5}$. The infection may present as pulmonary infiltrate or a mass which can involve the pleura, pericardium and chest wall leading to sinus tract formation ${ }^{6}$. Due to nonspecific and varied clinical and radiologic presentations diagnosis of pulmonary actinomycosis is difficult and often lead to delayed diagnosis or misdiagnosis as tuberculosis, lung abscess or lung cancer ${ }^{7,8}$. Weese at al reported a case series where only
$3 \%(6 / 194)$ cases were initially diagnosed as actinomycosis ${ }^{8}$. Additionally, improved oral hygiene and early antibiotic use has resulted in decreased incidence of the disease and less aggressive presentation compared with preantibiotic era9 ${ }^{9}$. So, diagnosis of actinomycosis is now even more challenging than before especially in limited facility situations like Bangladesh $^{10}$.

\section{The Case:}

The patient was a 53 year-old male, presented with 18 months history of multiple discharging sinus from chest wall and one month history of left lateral chest pain and cough. He had been well at about one and half year back when he noticed gradual development of a painful swelling over the left chest wall just lateral to xiphisternum. It was excised surgically but was not healing despite antibiotic and regular dressing. A month later he developed another swelling and subsequently three more swelling in the left anterior chest. He got admitted to hospital in a surgery ward. He was investigated and complete blood count revealed hemoglobin $10.5 \mathrm{mg} / \mathrm{dl}$, total leukocyte count $11,300 / \mathrm{mm}^{3}$,

1. Md. Zakiul Hassan, Honorary Medical Officer, Department of Medicine, Shaheed Suhrawardy Medical College Hospital, Dhaka

2. Md. Nazim Uddin, Medical Officer, Department of Medicine, Shaheed Suhrawardy Medical College Hospital, Dhaka

3. H. M. Nazmul Ahsan, Assistant Professor, Department of Medicine, Shaheed Suhrawardy Medical College Hospital, Dhaka

Corresponds to: Md. Zakiul Hassan, Honorary Medical Officer, Department of Medicine, Shaheed Suhrawardy Medical College Hospital, Dhaka. Email: luikaz32@yahoo.com 
$66 \%$ Neutrophil, normal thrombocytes and an ESR of $118 \mathrm{~mm}$ in first hour. Routine Urine examination revealed normal except one plus albumin. His Random blood sugar was $105 \mathrm{mg} /$ dl, sputum AFB was negative and induration at Monteux test was $6 \mathrm{~mm}$. The pus was examined and was negative for Gram or AFB stained organisms and culture yielded no growth. Chest $\mathrm{X}$-ray revealed left sided hydropneumothorax with collapse, consolidation of left lung. The radiological description of the chest X-ray wasleft dome of diaphragm is obscured, mediastinum shifted to the left, obscured left heart border, not delineated, homogeneously dense opacity was noted in left upper and mid zone, another dense opacity with a fluid level was seen in left hemi thorax along lateral chest wall, and anterior rib crowding was present on left side. With these investigation reports the patient was referred to the medicine unit. In the medicine ward revised further history evaluation revealed past history of left pleural effusion treated as TB pleural effusion 25 years back and was treated with AntiTB drugs discontinued of his own after 3 months. The patient also gave a history of mandible fracture and truth extraction two years back. The patient was physically examined and laboratory evaluation was negative for active TB. The case was suspected for a thoracic actinomycosis, as the patient complained of discharge of small granular substances from the sinuses during revision of case history. New investigations were planned and sent accordingly with repeating couple of investigations. Repeated CBC showed hemoglobin $9.2 \mathrm{mg} / \mathrm{dl}$, total leukocyte count $9,000 / \mathrm{mm}^{3}$ with $71 \%$ polymorphs and ESR was $80 \mathrm{~mm}$ in first hour. Pus was sent for Gram staining, AFB staining, culture and sensitivity and PCR for MTB DNA. The results were negative on PCR and culture but showed gram negative filamentous bacteria with significant number of sulphur granules. The gram stain was repeated and revealed similar results and a diagnosis of thoracic actinimycosis.

\section{Discussion:}

We report the case to inform clinicians that Actinomycosis should be suspected in cases with chronic discharging sinuses in the chest or pulmonary lesions suspecting smear negative PTB and not responding to Anti-TB medications. Actinimycosis is more common in male $(3: 1)$ and can affect all age group but common between 20 and 50 years $^{8}$. Risk factors includes poor dental hygiene or dental caries, pre existing structural lung disease, chronic alcoholism and cognitive delay ${ }^{11,12}$. Inhalation of contaminated aerosol particles or aspiration of oropharyngeal or gastrointestinal secretions, or hematogenous spread from a distant lesion is the mechanisms for pulmonary actinomycosis ${ }^{13,14}$. In our case the patient had a history of mandible fracture and tooth extraction two years before the onset of illness and had poor oral hygiene with severe caries, so secondary aspiration might have been the mechanism of infection. Actinomycosis may spread from the lung to the pleura, mediastinum and chest wall, with little regard for anatomic barriers. The organisms produce proteolytic enzymes, and peripheral pneumonia tends to involve the pleura, producing empyema, and invade the chest wall with involvement of bones such as the ribs or vertebrae ${ }^{15,16}$. Chest wall involvement is an uncommon manifestation, contributing to $12 \%$ of thoracic actinomycosis 3 . Chest wall involvement is usually preceded by lung infection, but may occur by means of a direct extension from the neck, esophagus, abdomen or retro peritoneum ${ }^{17}$. Chest wall involvement is much less common now than previously reported due to early antibiotic treatment ${ }^{16}$.

Radiological manifestations of chest wall involvement include a soft tissue chest wall mass continuous with pulmonary disease, with or without central low-attenuation, empyema, periosteal proliferation along the ribs, and destruction of ribs or vertebrae ${ }^{16}$. Pulmonary infections, which can produce similar findings of contiguous chest wall invasion, are tuberculosis, blastomycosis, nocardiosis, cryptococcosis and invasive aspergillosis. Other differential diagnoses are lymphoma, bronchogenic carcinoma, malignant mesothelioma and rare chest wall tumors ${ }^{16}$.

Definitive diagnosis of actinomycosis is made by examining the specimen from draining sinus, sulphur granule, deep needle aspirate or by biopsy $^{3}$. Gram stain and microscopy demonstrate filamentous, branched gram-positive rod. Isolation and identification of actinomyces in anaerobic culture require $2-3$ weeks ${ }^{18}$.

The treatment of choice is penicillin. In severe or rapidly progressive cases, penicillin should be started intravenously at high doses( 10-20 × 106 $\mathrm{IU} / \mathrm{d})^{3}$. Treatment duration is variable depending 
on the location and therapeutic response. Tetracyclines or macrolides are alternatives in case of resistance or allergy to penicillin ${ }^{19}$. Surgery is indicated for empyema drainage, fistula repair, and resection of destroyed lung tissue ${ }^{6}$.

\section{Conclusion:}

Thoracic actinomycosis is extremely rare and presents with nonspecific symptoms, an insidious course, and a variety of clinical manifestations. Failure to early diagnosis and appropriate treatment leads to significant morbidity including unwanted surgery. The prognosis is excellent with low mortality when the disease is recognized early and appropriate treatment is given. So it is worthy to consider actinomycosis as part of the differential diagnosis when confronted with chronic unresolving pulmonary lesion.

\section{References:}

1. Brown JR. Human actinomycosis: a study of 181 subjects. Human pathology 1973;4(3):319-30. http://dx.doi.org/10.1016/S0046-8177(73)80097-8

2. Brook I. Actinomycosis: diagnosis and management. Southern medical journal 2008;101(10):1019-23. http://dx.doi.org/10.1097/SMJ.0b013e3181864c1f

3. Zarca-diaz de la Espina MA, Lopez-Menendez C, Ruiz-Martinez R, Molino-Trinidad C. Pulmonary actinomycosis with thoracic soft tissue mass: a rare onset form. European journal of radiology 2001;37(3):195-9. http://dx.doi.org/10.1016/S0720-048X(00)00257-6

4. Bates M, Cruickshank G. Thoracic actinomycosis. Thorax 1957;12(2):99-124. http://dx.doi.org/10.1136/thx.12.2.99

5. Kim TS, Han J, Koh W-J, Choi JC, Chung MJ, Lee $\mathrm{JH}$, et al. Thoracic actinomycosis: CT features with histopathologic correlation. American Journal of Roentgenology 2006;186(1):225-31. http://dx.doi.org/10.2214/AJR.04.1749

6. Lu M-S, Liu H-P, Yeh C-H, Wu Y-C, Liu Y-H, Hsieh $\mathrm{M}-\mathrm{J}$, et al. The role of surgery in hemoptysis caused by thoracic actinomycosis; a forgotten disease. European journal of cardio-thoracic surgery 2003;24(5):694-8. http://dx.doi.org/10.1016/S1010-7940(03)00515-3

7. Moniruddin A, Begum H, Nahar K. Actinomycosis: an update. Medicine today 2010;22(1):43-7. http://dx.doi.org/10.3329/medtoday.v22i1.5606

8. Weese WC, Smith IM. A study of 57 cases of actinomycosis over a 36-year period. A diagnostic'failure'with good prognosis after treatment. Archives of internal medicine 1975;135(12):1562. http://dx.doi.org/10.1001/archinte.1975.00330120040006

9. Mandell GL. Mandell, Douglas, and Bennett's principles and practice of infectious diseases. 2005.

10. Volante M, Contucci A, Fantoni M, Ricci R, Galli J. Cervicofacial actinomycosis: still a difficult differential diagnosis. Acta otorhinolaryngologica italica 2005;25(2):116.
11. Hermida MD, Della Giovanna P, Lapadula M, García S, CabreraHN.Actinomycesmeyericutaneousactinomycosis. International journal of dermatology 2009;48(2):154-6. http://dx.doi.org/10.1111/j.1365-4632.2009.03798.x

12. Bartlett AH, Rivera AL, Krishnamurthy R, Baker CJ. Thoracic actinomycosis in children: case report and review of the literature. The Pediatric infectious disease journal 2008;27(2):165-9. http://dx.doi.org/10.1097/inf.0b013e3181598353

13. Fatureto MC, Oliveira PF, Almeida COR, Fernandes LHG. Lung actinomycosis with chest wall involvement. Revista da Sociedade Brasileira de Medicina Tropical 2007;40(1):82-5.

14. Marques AS, Lopes N, Guimarães M, Vera J, Monteiro $\mathrm{M}$, Serrano I, et al. Actinomicose pulmonar-A propósito de um caso clínico. Revista Portuguesa de Pneumologia (English Edition) 2007;13(2):275-80. http://dx.doi.org/10.1016/S2173-5115(07)70333-0

15. Cheon J-E, Im J-G, Kim MY, Lee JS, Choi GM, Yeon KM. Thoracic actinomycosis: CT findings. Radiology 1998;209(1):229-33. http://dx.doi.org/10.1148/radiology.209.1.9769836

16. Webb W, Sagel S. Actinomycosis involving the chest wall: CT findings. American Journal of Roentgenology 1982;139(5):1007-9. http://dx.doi.org/10.2214/ajr.139.5.1007

17. Hsieh M-J, Liu H-P, Chang J-P, Chang C-H. Thoracic actinomycosis. CHEST Journal 1993;104(2):366-70. http://dx.doi.org/10.1378/chest.104.2.366

18. Smego Jr RA, Foglia G. Actinomycosis. Clinical infectious diseases. 1998:1255-61.

19. Kabiri M, Zidane A, Arsalane A, Kabiri E. [Pulmonary actinomycosis in a child]. Archives de pediatrie: organe officiel de la Societe francaise de pediatrie 2008;15(8):1312-4. http://dx.doi.org/10.1016/j.arcped.2008.05.002 